\title{
Effect of Calcimimetic Agent, KRN568, on Gastrin Secretion in Healthy Subjects
}

\author{
Tetsuya IGARASHI, Etsuro OGATA*, KAZUnobu MARUYAMA**, TsUyoshi FUKUDA*** AND \\ JUNICHI AZUMA***
}

Department of Internal Medicine, University of Tokyo Branch Hospital, University of Tokyo, Tokyo 112-8688, Japan

* Cancer Institute Hospital, Tokyo 170-8455, Japan

** Osaka Pharmacology Research Clinic, Osaka 565-0853, Japan

*** Clinical Evaluation of Medicines and Therapeutics, Graduate School of Pharmaceutical Sciences, Osaka University, Osaka 565-0871, Japan

\begin{abstract}
KRN568 is a calcimimetic compound which acts on the calcium sensing receptors (CaR) on the parathyroid gland to suppress secretion of PTH. A recent report has demonstrated that CaRs are expressed on cultured human antral gastrin cells and that gastrin secretion is stimulated by an increase in extracellular calcium level. However, the effect of KRN568 on serum gastrin levels has yet to be clinically assessed. We therefore studied the effect of this calcimimetic on gastrin secretion in healthy subjects enrolled in the phase 1 study for KRN568 currently carried out in Japan. Single doses of KRN568, ranging from $25 \mathrm{mg}$ to $400 \mathrm{mg}$, were orally administered to 6 healthy male volunteers at fasting and after meal. One subject proved to be a poor metabolizer (PM) for this compound and showed more than 10-fold high concentrations of plasma KRN568 (fasting Cmax 90.8 and non-fasting $83.8 \mathrm{ng} / \mathrm{ml}$ ) compared to the other 5 individuals (Cmax $6.5 \pm 2.2$ and $7.4 \pm 1.6 \mathrm{ng} / \mathrm{ml}$, respectively). Plasma gastrin levels showed mild but apparent increase (from 30 to $125 \mathrm{pg} / \mathrm{ml}$ ) in this particular subject, while there were no significant increases in the other five people (from $34 \pm 6$ to $63 \pm 3 \mathrm{pg} / \mathrm{ml}$ ) after oral administration of $400 \mathrm{mg}$ KRN568 at fasting. In the PM, administration of KRN568 resulted in extraordinarily high serum drug levels associated with transient increase of gastrin levels. This observation suggested that calcium-induced stimulation of gastrin secretion in human was mediated by a mechanism involving CaR. Potential side effects related to the increased gastrin secretion may be warranted in the practical use of this compound.
\end{abstract}

Key words: Calcimimetics, Calcium-sensing receptor, Gastrin

(Endocrine Journal 47: 517-523, 2000)

GASTRIN is a polypeptide hormone synthesized and secreted from the gastric antral G-cells. Gastrin secretion is especially enhanced by ingestion of foods rich in proteins or amino acids, and suppressed by somatostatin during antral acidification [1]. It is also influenced by various extracellular stimuli including serum calcium. Sustained elevation of serum calcium is often associated with high serum

Received: February 4, 2000

Accepted: May 17, 2000

Correspondence to: Dr. Tetsuya IGARASHI, Department of Internal Medicine, University of Tokyo Branch Hospital, 328-6, Mejirodai, Bunkyo-ku, Tokyo 112-8688, Japan gastrin levels which might contribute to the occasional association of ulcer diseases in hypercalcemic patients. KRN568 is a calcimimetic compound which acts on $\mathrm{CaR}$ in the parathyroid gland to suppress secretion of PTH [2]. Recently, Ray et al. reported that $\mathrm{CaRs}$ are expressed on the plasma membrane of cultured human antral gastrin cells and that increased extracellular calcium or spermine, a known CaR agonist, stimulated gastrin secretion from those cells, suggesting that CaR might be involved in this regulation [3]. As KRN568 is postulated to have similar action, this would be a potential drawback in the clinical application of calcimimetics, especially when used in large doses over a long period 
of time. The phase 1 clinical trials of KRN568 have been finished recently in Japan and confirmed the clinical usefulness and overall safety of this compound with Japanese population. Our concern that KRN568 might induce enhanced secretion of gastrin in the clinical situation prompted us to study the gastrin levels after its administration to the participants in the phase 1 trials who gave their informed consent.

\section{Subjects and Methods}

\section{Clinical trial}

The phase 1 study was designed as a single-dose oral, open-labeled and stepwise dosing protocol from 25 to $400 \mathrm{mg}$. Each of six healthy male volunteers, aged from 20 to 25 , was subjected to this trial study both at fasting and after meal ("non-fasting" in Figs. 2-4 and Table 1). Plasma samples were taken before dosing and $0.5,1,2,4,8,12,24$ and $48 \mathrm{hr}$ after dosing. Portions of those samples remained after finishing the complete phase 1 study including biochemical parameters were utilized for immunoradiometric assay of gastrin (Gastrin RIA kit 2, Dainabot Co., Ltd., Tokyo).

\section{Genotyping of Cytochrome P450}

Genomic DNA was isolated from peripheral lymphocytes of each subjects. The genotype of CYP2D6 was determined according to the method of Fukuda et al. [4]. CYP2D6*10 (exon1: 188C $\rightarrow$ $\mathrm{T}$, exon9: $4268 \mathrm{G} \rightarrow \mathrm{C}$ ) and $C Y P 2 D 6^{*} 2$ (exon6: $2938 \mathrm{C} \rightarrow \mathrm{T}$ ) were detected by cleavage of PCR products by restriction enzyme Hph I, Hha I and Ban II, respectively. $X b a$ I restriction fragment length polymorphism (RFLP) analysis was performed to detect $C Y P 2 D 6^{*} 5$, which lacks one entire allele of CYP2D6 (Fig. 1), according to the method of Steen et al. [5]. CYP2C19*1 and two defective forms, $C Y P 2 C 19^{*} 2$ and $C Y P 2 C 19^{*} 3$, were identified by PCR-RFLP analysis previously described by de Morais et al. [6] with minor modifications. After PCR amplification using specific primers, each product was digested with restriction enzymes Msp I and Bam HI [7]. All analyses were performed with informed consent.

\section{Measurement of plasma KRN568 concentrations}

Portions of plasma samples collected before dosing and $0.5,1,2,3,4,6,8,12,24$ and $48 \mathrm{hr}$ after dosing were used for pharmacokinetics of KRN568. The concentrations of KRN568 and its metabolites were measured by gas chromatography and mass spectrophotometry in the Mitsubishi-Kagaku Bioclinical Laboratory Inc., Tokyo.

\section{Results and Discussion}

Calcium is known to increase serum gastrin levels by activation of neural pathways or direct stimulation of antral G-cells. The recent discovery of membrane-associated Ca-sensing receptors $(\mathrm{CaR})$ has opened the way to the study of the mechanism whereby calcium modulates various physiological cellular events [8]. Ray et al. have shown that the

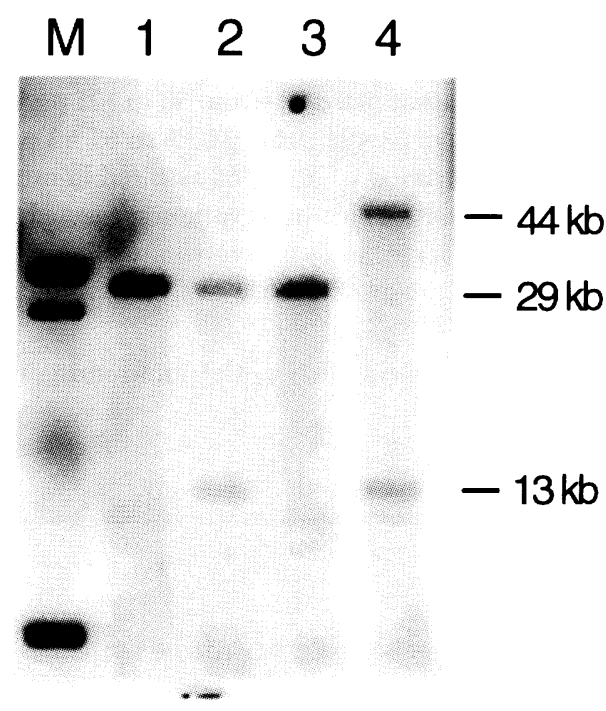

Fig. 1. Xba I-RFLP analysis of genomic DNA. Southern blotting was carried out using CYP2D6 cDNA as a probe (lanes: $M$ for the size marker and 1 to 4 for subject numbers). Since the restriction fragment of allele CYP2D6 includes the preceding pseudogenes CYP2D8 and CYP2D7, it was detected as 29-kb bands (subjects \#1 to \#3). The deletion of an entire CYP2D6, the allele CYP2D6*5, resulted in a $13-\mathrm{kb}$ fragment indicating only the chain of the pseudogenes detected by the same probe (subjects \#2 and \#4). A 44-kb fragment was detected in subject \#4 representing CYP2D6*10, the product of which has the weakest enzyme activity [19]. Thus, the genotype of the poor metabolizer in our study is $*_{5} /{ }^{*} 10$. 
A

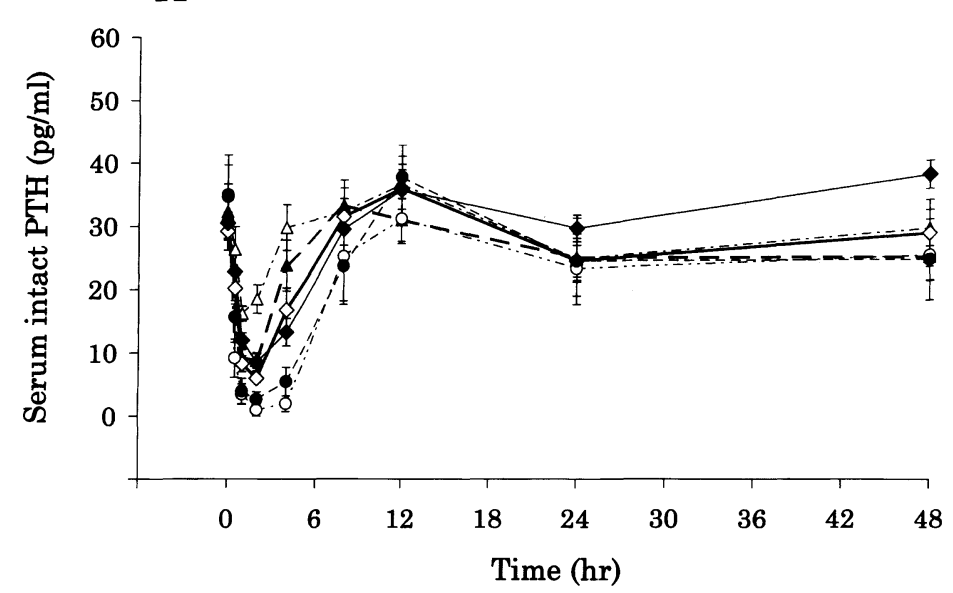

B

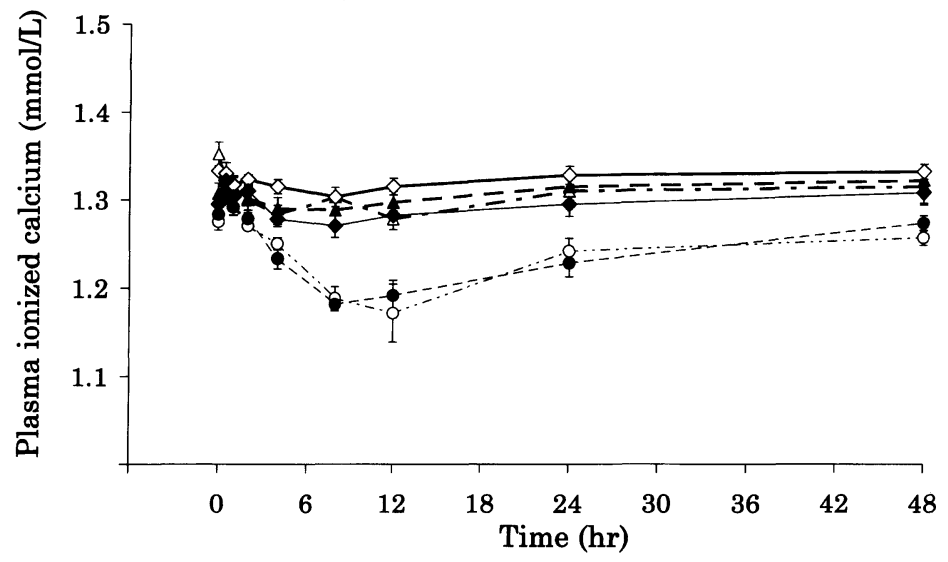

C

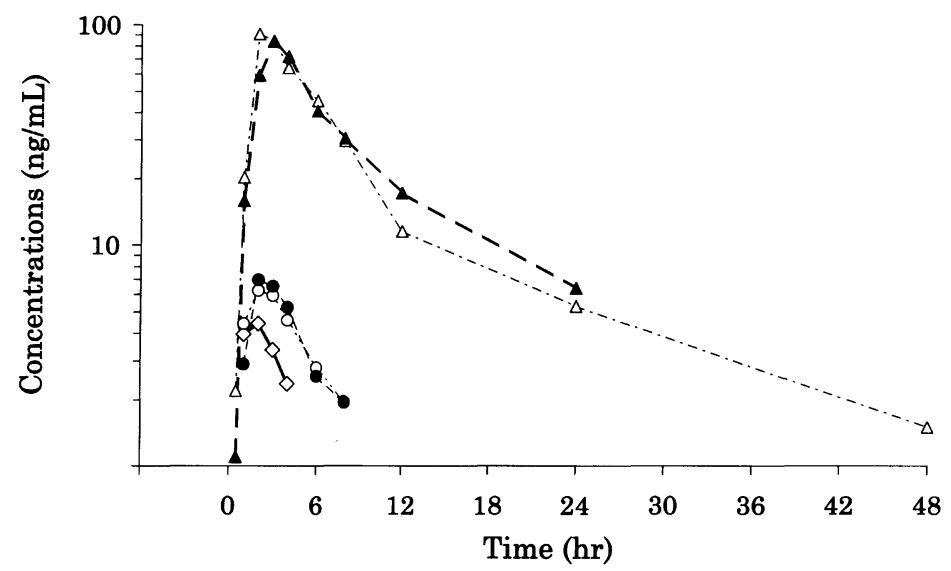

Fig. 2. Hypocalcemic effects of KRN568 in phase 1 clinical trial. Twenty-five to $400 \mathrm{mg}$ of KRN568 was administered to 6 healthy volunteers in the phase 1 clinical trial (for panels A and B, $\triangle-\cdot-\cdot-\triangle 25 \mathrm{mg} ; \Delta---\Delta 50 \mathrm{mg} ; \diamond-\diamond 100 \mathrm{mg}$; $\bullet-200 \mathrm{mg} ; \bigcirc-\cdots-. . \bigcirc 400 \mathrm{mg}$, fasting; $\bullet---400 \mathrm{mg}$, non-fasting; Data represent means \pm SE). The effect of calcimimetic was evident in terms of decreases both in plasma PTH (panel A) and ionized calcium levels (panel B) at $400 \mathrm{mg}$. One of the subjects tested was a poor metabolizer (PM) showing remarkably higher concentrations of KRN568 after oral administration than the other 5 normal metabolizers (NM) (panel C, $\triangle-\cdot-\cdot-\triangle$ PM, fasting; $\Delta---\Delta$ PM, non-fasting; $\bigcirc-\ldots \ldots \circ \mathrm{NM}$, fasting; $\bullet--\bullet \mathrm{NM}$, non-fasting; $\diamond \smile \diamond \mathrm{NM}, 200 \mathrm{mg}$; Data of $5 \mathrm{NMs}$ represent averages). 
extracellular $\mathrm{CaR}$ identical to that of parathyroid cells is expressed on human antral gastrin cells by reverse transcription PCR, immunocytochemistry and Western blots of whole cell lysates with a specific antibody [3]. They have also shown that an increase in extracellular calcium levels stimulates gastrin release in a concentration-dependent manner, indicating that the activation of CaR may explain the acid rebound phenomenon associated with calciumcontaining antacid preparations. Transcripts similar to those in the parathyroid and kidney have been detected in rat gastric mucosal poly $\mathrm{A}+$ RNA by Cheng et al., who suggest that the effects of extracellular $\mathrm{Ca}^{2+}$ on gastric function may be attributable to activation of $\mathrm{CaR}$ [9].

Calcimimetics that interact with $\mathrm{CaR}$ to enhance calcium action on CaR have been developed by NPS Pharmaceuticals (Salt Lake City, UT, USA) and Kirin Brewery Co. (Tokyo, Japan) and have been studied extensively for their clinical usefulness as well as safety [10]. Clinical application has already been successfully started in a patient with parathyroid cancer [11], those with primary hyperparathyroidism [12] and hemodialysis patients with secondary hyperparathyroidism [13]. Recently, phase 1 clinical trial of KRN568 has been conducted with healthy male volunteers in Japan. Various amounts of KRN568 from $25 \mathrm{mg}$ to $400 \mathrm{mg}$ were administered to each of six healthy male volunteers at fasting and after meal. Since the hypocalcemic effect of the compound was variable depending on the individuals tested in the single-dose clinical trial performed in the United States (personal communication with NPS Pharmaceuticals), polymorphism of cytochrome P450 was suspected as a cause, which has turned out to be the case in our study. Genotyping for CYP2D6 and $2 \mathrm{C} 19$, which are the predominant enzyme and bypass enzyme metabolizing KRN568, respectively, was thus carried out with all volunteer participants after obtaining fully informed consent. It was revealed that KRN568 had considerable ability to suppress PTH secretion and to decrease serum calcium levels (Fig. 2, panels A and B), but that no specific, serious and long-lasting side effects were observed during the period of administration and the subsequent one month (details to be published elsewhere). Increased serum phosphate, urinary excretion of calcium and decreased urinary excretion of phosphate were observed in parallel, which are compatible with suppression of PTH (data not shown). One subject was revealed to have CYP2D6 gene mutation $\left(2 \mathrm{D} 6 * 5 /{ }^{*} 10\right)$ and his poor metabolizing capacity for KRN568 was confirmed by detection of more than 10-fold high concentrations of plasma KRN568 (Cmax 90.8 at fasting and $83.8 \mathrm{ng} / \mathrm{ml}$ after meal) compared to the other five individuals (Cmax $6.5 \pm 2.2$ and $7.4 \pm 1.6 \mathrm{ng} / \mathrm{ml}$, respectively) after administration of $400 \mathrm{mg}$ (Fig. 2, panel $\mathrm{C}$ and Table 1). This mutation, however, causes weaker enzyme activity only for KRN568 but not for any other substrates. Plasma gastrin levels showed mild but apparent increases (from 30 to $125 \mathrm{pg} / \mathrm{ml}$ ) in this particular case, while there were no significant increases in the other five people (from $34 \pm 6$ to $63 \pm 3 \mathrm{pg} / \mathrm{ml}$ ) after administration of KRN568 (Fig. 3, panels A and B). The difference between these groups is not statistically significant because of the single poor metabolizer, but reasonably significant because an intravenous calcium infusion test, which is employed to detect an exaggerated response in gastrinoma patients, usually shows minimal or less than $50 \%$ increase over basal values when employed in normal subjects [14]. Plasma PTH and serum calcium levels were suppressed for longer duration in the poor metabolizer than in the normal ones (Fig. 4, panels A and B). This was compatible with the difference of pharmacokinetics between the two groups. These observations suggested that calcium-induced stimula-

Table 1. Pharmacokinetic parameters of KRN568 when $400 \mathrm{mg}$ was administered.

\begin{tabular}{ccccc}
\hline & & Cmax (ng/ml) & AUC (ng $\cdot \mathrm{hr} / \mathrm{ml})$ & tmax (hr) \\
\hline Normal metabolizer & Fasting & $6.4 \pm 1.6$ & $40.5 \pm 8.6$ & $2.4 \pm 0.6$ \\
$(\mathrm{n}=5)$ & Non-fasting & $7.4 \pm 1.1$ & $44.0 \pm 5.3$ & $2.4 \pm 0.5$ \\
\hline Poor metabolizer & Fasting & 90.8 & 700 & 2 \\
$(\mathrm{n}=1)$ & Non-fasting & 83.8 & 689 & 3 \\
\hline
\end{tabular}



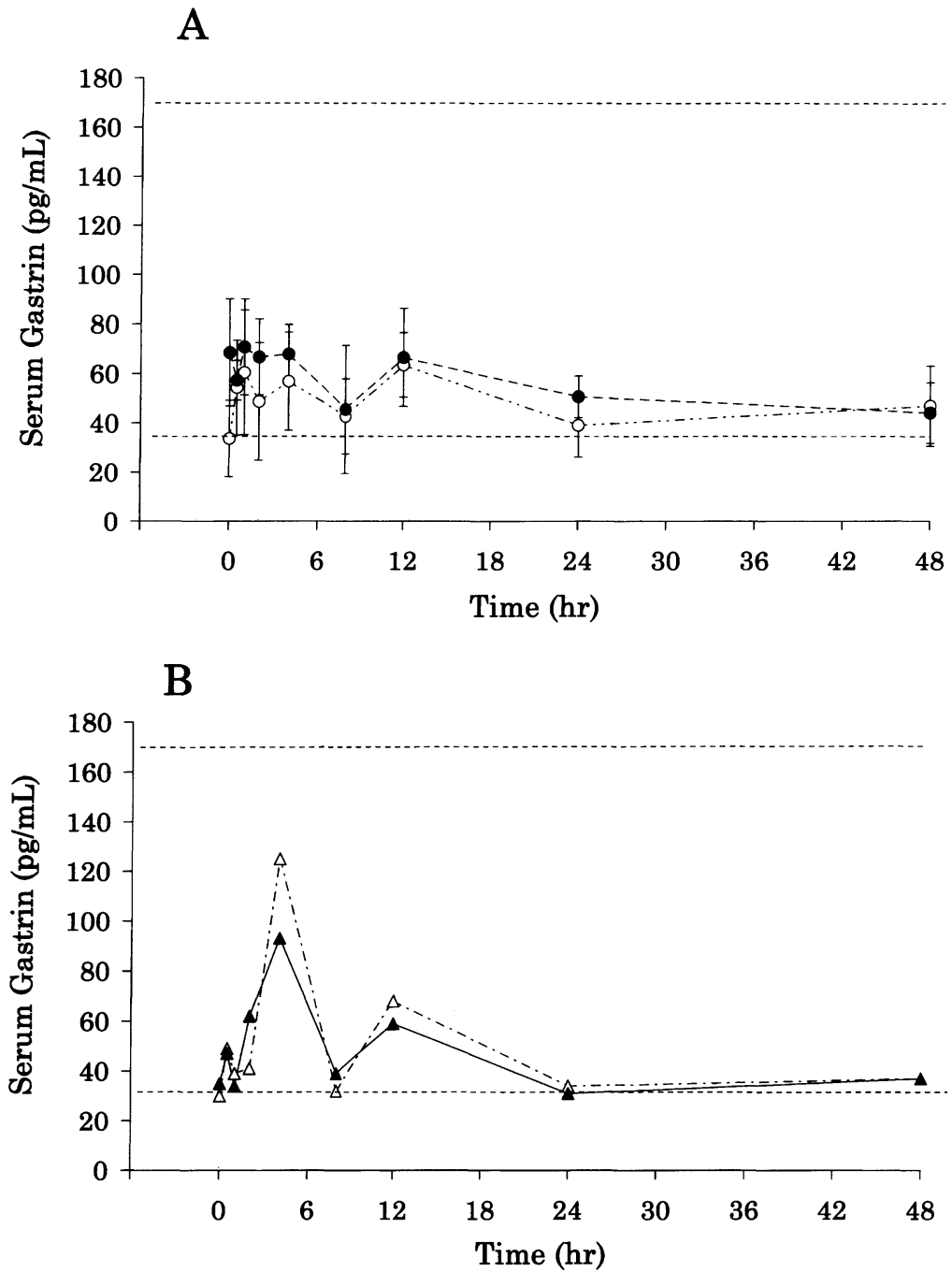

Fig. 3. Enhancement of gastrin secretion by KRN568 in a poor metabolizer. Serum gastrin levels were determined after administration of $400 \mathrm{mg}$ KRN568 to 5 normal metabolizers (panel A, $\bigcirc-. .-.-\bigcirc$ fasting; $\bullet$--_-- $\bullet$ non-fasting, Data represent means $\pm \mathrm{SE}$ ) and one poor metabolizer (panel B, $\triangle-\cdot-\cdot \triangle$ fasting; $\Delta-\Delta$ non-fasting) as described in the text. Although they fluctuated within normal range in either case, the serum levels of gastrin increased reaching a peak at $4 \mathrm{hrs}$ after administration.

tion of human gastrin secretion in vivo was mediated by a mechanism involving CaR. Since PTH levels were suppressed by a much smaller amount of KRN568 as low as $25 \mathrm{mg}$ (data not shown), the CaR-mediated mechanism of parathyroid glands seemed to be more sensitive to the changes in extracellular calcium concentration than that of antral gastrin cells.

Although KRN568 has been proved a safe agent for clinical use and no direct GI side effects have been reported with this compound in any of the previous papers [15], there is the possibility that it can cause continuous gastrin hypersecretion in poor metabolizers when used frequently in large doses over a long period. The poor metabolizer in our study harbors one allele producing an enzyme with the weakest activity $($ CYP2D6*10) and lacks another allele encompassing the entire region of the CYP2D6 gene (CYP2D6*5) (Fig. 1, subject \#4). Incidence of CYP2D6 $6 /{ }^{*} 10$ in the Japanese population is $3 \%$, while those of alleles CYP2D6*5 and CYP2D6*10 are $4.5 \%$ and $38.1 \%$, respectively [16]. Because the incidence of slow metabolizers in the Japanese population is far less than in Caucasians [17], these 


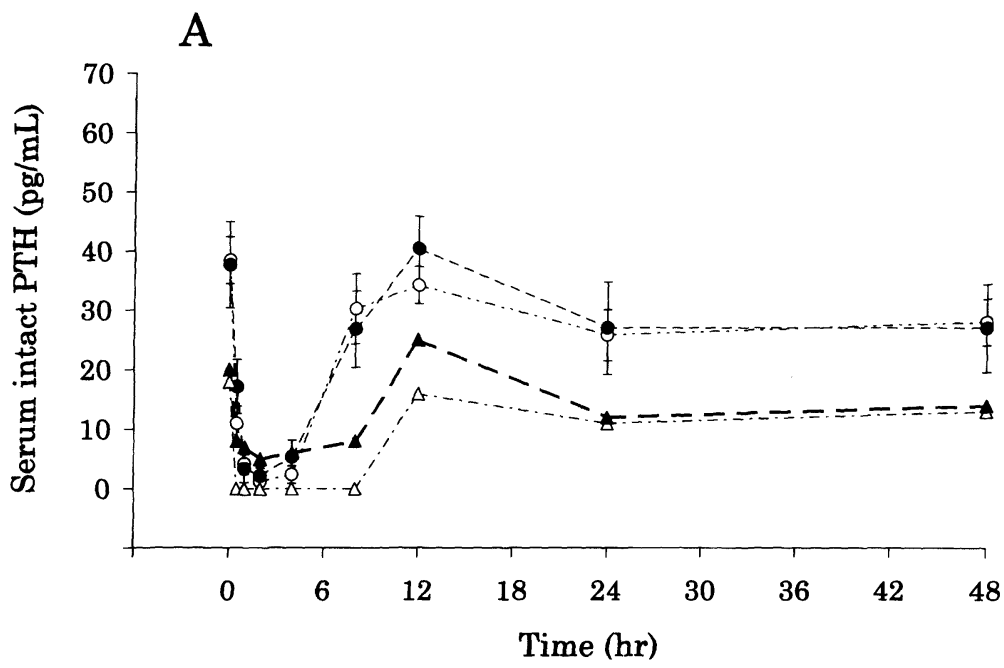

B

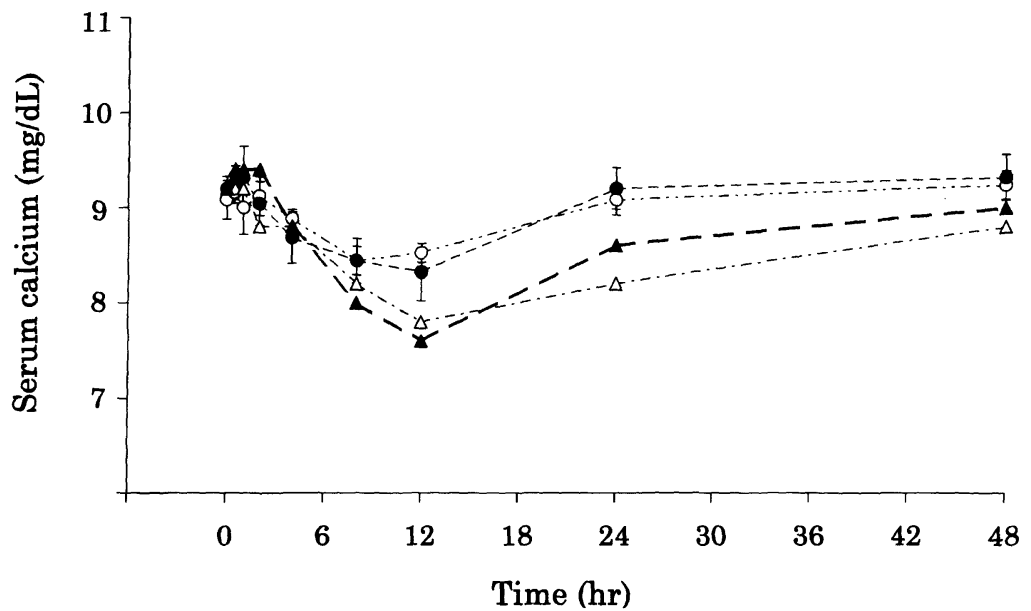

Fig. 4. Effects of KRN568 in a poor metabolizer. Decremental effects of $400 \mathrm{mg}$ KRN568 on the plasma PTH and serum calcium levels were compared between normal metabolizers (NM) and one poor metabolizer (PM). Both PTH-lowering (panel A) and hypocalcemic (panel B) effects lasted longer in the poor metabolizer than in the normal metabolizers (for both

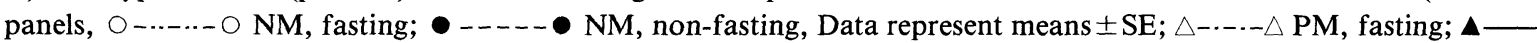
$\triangle$ PM, non-fasting). Duration of PTH-suppression was almost the same as that of gastrin-stimulation (Fig. 2).

considerations may not be so serious but they are still worthy of note. In addition, it may be noteworthy that cimetidine or ranitidine, $\mathrm{H} 2$-blockers inhibiting CYP2D6, has a good chance to be effectively administered to hypercalcemic patients to relieve abdominal discomfort, but that simultaneous use with KRN568 will result in poor degradation of both drugs [18]. Calcimimetics of the next generation which are not affected by polymorphism of metabolic enzymes are awaited to achieve clinical satisfaction.

\section{Acknowledgements}

We thank Y. Furuya, J. Ishida, H. Murakoshi, M. Nakagawa, and J. Koumegawa, Kirin Brewery Company, Tokyo, for organizing the phase 1 clinical trial and their assistance in performing the biochemical and pharmacological measurements. 


\section{References}

1. Bloom SR, Polak JM (1995) The endocrine gastrointestinal tract: Pathophysiology. In Principles and Practice of Endocrinology and Metabolism. Becker KL (ed) JB Lippincott Co., Philadelphia, 1499-1512.

2. Nemeth EF, Steffey ME, Hammerland LG, Hung BC, Van Wagenen BC, Del Mar EG, Balandrin MF (1998) Calcimimetics with potent and selective activity on the parathyroid calcium receptor. Proc Natl Acad Sci USA 95: 4040-4045.

3. Ray JM, Squires PE, Curtis SB, Meloche MR, Buchan AM (1997) Expression of the calcium-sensing receptor on human antral gastrin cells in culture. J Clin Invest 99: 2328-2333.

4. Fukuda T, Yamamoto I, Nishida Y, Zhou Q, Ohno M, Takada K, Azuma J (1999) Effect of the CYP2D6*10 genotype on venlafaxine pharmacokinetics in healthy adult volunteers. $\mathrm{Br} \mathrm{J}$ Clin Pharmacol 47: 450-453.

5. Steen VM, Andreassen OA, Daly AK, Tefre T, Borresen AL, Idle JR, Gulbrandsen AK (1995) Detection of poor metabolizer-associated CYP2D6 (D) gene deletion allele by long-PCR technology. Pharmacogenetics 5: 215-223.

6. de Morais SMF, Wilkinson GR, Blaisdell GRJ, Nakamura K, Meyer UA, Goldstein JA (1994) Identification of a new genetic defect responsible for the polymorphism of S-mephenytoin metabolism in Japanese. Mol Pharmacol 46: 594-598.

7. Zhou Q, Yamamoto I, Fukuda T, Ohno M, Sumida A, Azuma J (1999) CYP2C19 genotypes and omeprazole metabolism after single and repeated dosing when combined with clarithromycin. Eur $J$ Clin Pharmacol 55: 43-47.

8. Brown EM, Pollak M, Hebert SC (1998) The extracellular calcium-sensing receptor: its role in health and disease. Annu Rev Med 49: 15-29.

9. Cheng I, Qureshi I, Chattopadhyay N, Qureshi A, Butters RR, Hall AE, Cima RR, Rogers KV, Hebert SC, Geibel JP, Brown EM, Soybel DI (1999) Expression of an extracellular calcium-sensing receptor in rat stomach. Gastroenterology 116: 118-126.

10. Nemeth EF, Fox J (1999) Calcimimetic compounds: a direct approach to controlling plasma levels of para- thyroid hormone in hyperparathyroidism. Trends in Endocrinology and Metabolism 10: 66-71.

11. Collins MT, Skarulis MC, Bilezikian JP, Silverberg SJ, Spiegel AM, Marx SJ (1998) Treatment of hypercalcemia secondary to parathyroid carcinoma with a novel calcimimetic agent. J Clin Endocrinol Metab 83: 1083-1088.

12. Silverberg SJ, Bone HG, 3rd, Marriott TB, Locker FG, Thys-Jacobs S, Dziem G, Kaatz S, Sanguinetti EL, Bilezikian JP (1997) Short-term inhibition of parathyroid hormone secretion by a calcium-receptor agonist in patients with primary hyperparathyroidism. N Engl J Med 337: 1506-1510.

13. Antonsen JE, Sherrard DJ, Andress DL (1998) A calcimimetic agent acutely suppresses parathyroid hormone levels in patients with chronic renal failure. Rapid communication. Kidney Int 53: 223-227.

14. Lamers CG, Van Tongeren JH (1977) Comparative study of the value of the calcium, secretin, and meal stimulated increase in serum gastrin to the diagnosis of the Zollinger-Ellison syndrome. Gut 18: 128-135.

15. Coburn JW, Maung HM (2000) Calcimimetic agents and the calcium-sensing receptor. Curr Opin Nephrol Hypertens 9: 123-132.

16. Nishida Y, Fukuda T, Yamamoto I, Azuma J (2000) The CYP2D6 genotypes in a Japanese population; low frequencies of CYP2D6 gene duplication but high frequency of CYP2D6*10. Pharmacogenetics (in press).

17. Sachse C, Brockmoller J, Bauer S, Roots I (1997) Cytochrome P450 2D6 variants in a Caucasian population: allele frequencies and phenotypic consequences. Am J Hum Genet 60: 284-289.

18. Hoensch HP, Hutzel H, Kirch W, Ohnhaus EE (1985) Isolation of human hepatic microsomes and their inhibition by cimetidine and ranitidine. Eur J Clin Pharmacol 29: 199-206.

19. Johansson I, Oscarson M, Yue QY, Bertilsson L, Sjoqvist F, Ingelman-Sundberg M (1994) Genetic analysis of the Chinese cytochrome P4502D locus: characterization of variant CYP2D6 genes present in subjects with diminished capacity for debrisoquine hydroxylation. Mol. Pharmacol 46: 452-459. 